\title{
MODEL AISAS DALAM KAMPANYE ANTI CYBERBULLYING 'NO BULL' KARYA MARA PANZAR
}

\author{
Elba Andrea ${ }^{1}$, Alvanov Zpalanzani Mansoor*2 \\ Institut Teknologi Bandung ${ }^{1,2}$ \\ *corresponding author: alvanov.mansoor@itb.ac.id
}

\begin{abstract}
Mara Panzar membuat kampanye anti-cyberbullying berjudul "No Bull" pada tahun 2011, dan memberikan penghargaan Pratt Circle Award pada tahun 2013 bagi kampanye yang dilakukan oleh organisasi nirlaba yang mengajarkan anak-anak bagaimana menghadapi dan mencegah cyberbullying untuk anak berusia 12-17 tahun. Kampanye menggunakan media yang terpadu meliputi poster kegiatan, karakter augmented reality, interaksi melalui email, desain pameran, jaringan online, teaser permainan interaktif, dan barang-barang promosi atau merchandise termasuk papercraft dan kaos. Penelitian ini bertujuan untuk menganalisis kampanye "No Bull" berdasarkan model komunikasi AISAS (Attention, Interest, Search, Action and Share) dengan hasil, model AISAS berperan penting dalam membangun preferensi pasar sasaran terhadap kampanye tersebut. Poster dan interaksi melalui email berperan dalam membangun awareness dan minat, sedangkan peta pada undangan dan stiker mural menginspirasi target audience untuk mencari informasi dengan berbagai kegiatan kolaboratif dan berinteraksi di area pameran melalui simulasi. Peserta kemudian berbagi pengalaman melalui papercraft dengan fitur augmented reality dan T-shirt untuk masyarakat luas. Penerapan model komunikasi AISAS dalam kampanye sosial mengubah pola komunikasi pesan kampanye dengan mengaktifkan peran khalayak sasaran dalam mendapatkan pesan kampanye, melaksanakan dan atau berpartisipasi, serta menjadi agen perubahan yang menyebarkan pesan kampanye sosial ke audience yang lebih luas.
\end{abstract}

Keywords: Model AISAS, Bullying, Cyberbullying, Media Terintegrasi, Kampanye Sosial

\begin{abstract}
Mara Panzar created an anti-cyberbullying campaign titled "No Bull" in 2011, and rewarded Pratt Circle Award in 2013 for a non-profit organization campaign that teaches kids how to deal with and prevent cyberbullying for 12-17 year olds. The campaign integrated media usage includes event posters, augmented reality characters, interactive self-mailers, an exhibit design, an online network, an interactive teaser game, and small promotional items or merchandises including papercraft and team shirts. This research aims to analyze "No Bull" campaign based on AISAS (Attention, Interest, Search, Action and Share) communication model with results, AISAS model plays a significant role in building target market's preference towards the campaign. Posters and interactive invitations play a role in building awareness and interest, while map on the invitation and the mural sticker inspire the target audience to search information with various collaborative activities and interact in exhibition area through simulations. Participants then share the experience through papercraft with augmented reality features and T-shirts for the wider community. The application of the AISAS communication model in social campaigns changes the communication pattern of campaign messages by activating the role of target audiences in getting campaign messages, implementing and or participating, as well as becoming agents of change who disseminate the social campaign message to a wider audience.
\end{abstract}

Keywords: AISAS Model, Bullying, Cyberbullying, Integrated Media, Sosial Campaign 


\section{Pendahuluan}

Bullying atau perundungan adalah salah satu masalah sosial, yaitu bentuk penyiksaan atau pelecehan yang dilakukan tanpa motif tapi dengan sengaja dilakukan berulang-ulang terhadap orang yang dianggap lebih lemah dengan ciri mudah menangis, mudah marah, dan mudah menyerah terhadap yang melakukan perundungan (American Academy of Pediatrics, 2013). Semua perilaku intimidasi baik secara fisik maupun psikis bahkan melalui tekanan sosial tergolong dalam bullying. Tindakan-tindakan seperti memukul, mendorong, mengancam, mengejek, dan melecehkan dapat kita temui dalam keseharian, terutama dalam lingkungan pergaulan. Kementrian Pemberdayaan Perempuan dan Perlindungan Anak memunculkan definisi bullying dengan bullying adalah segala bentuk penindasan atau kekerasan yang dilakukan dengan sengaja oleh satu atau sekelompok orang yang lebih kuat ataupun berkuasa terhadap orang lain yang dirasa lebih lemah, dengan tujuan menyakiti dan dilakukan secara terus menerus (Kementrian Pemberdayaan Perempuan dan Perlindungan Anak, 2017). Bullying akan berdampak buruk terhadap kedua pihak terutama dalam hal kestabilan emosi perundung dan korban. Bullying yang awalnya berbentuk konvensional melalui interaksi langsung sudah merambah ke bentuk yang baru: melalui interaksi dan komunikasi daring, khususnya melalui media sosial, atau yang biasa disebut dengan istilah cyberbullying (Hinduja dan Patchin, 2013). Cyberbullying atau perundungan maya adalah aktivitas perundungan yang dilakukan terhadap seseorang melalui gawai elektronik seperti computer, ponsel, dan perangkat elektronik lainnya (Cyberbullying Research Center, 2015). Secara umum, cyberbullying adalah fenomena bullying yang muncul ketika tiga komponen bersinggungan, yaitu, remaja, teknologi, dan masalah (Hinduja dan Patchin, 2015). Berdasarkan data statistik yang didapatkan dari i-SAFE Foundation, lebih dari setengah dari remaja pernah terlibat dalam kasus cyberbullying, dan jumlah korban yang melaporkan ke orang tua hanya 1 dari 10 remaja, melaporkan ke hukum kurang dari 1 dari 5 remaja, 1 dari 5 remaja mengungah dan mengirimkan konten seksual mereka ke orang lain (Teenhelp.com, 2015). Nancy E. Willard (2007) membuat klasifikasi aktivitas Cyberbullying ke dalam 8 kategori, yaitu flaming, harassment, denigration, impersonation, outing, trickery, exclution, dan cyberstalking. Berdasarkan liputan dari The Jakarta Post pada tahun 2019, bahwa hamper dari setengah pengguna media sosial Indonesia pernah mengalami Cyberbullying dalam bentuk flaming, harassment, dan denigration (The Jakarta Post, 2019).

Melalui jejaring internet, khususnya dalam komunikasi melalui media sosial dimana berbagai macam individu khususnya remaja dapat berinteraksi secara bebas namun dapat menyamarkan diri melalui akun palsu atau akun anonim. Nihilnya batasan tersebut membuat fenomena bullying menjadi masif dan tidak terkontrol. Dan seiring dengan perilaku yang makin masif tersebut, implikasi terhadap pihak terkait pun (perundung dan korban) makin besar pula. Hal tersebut menimbulkan dampak buruk terhadap kestabilan emosi individu maupun kestabilan interaksi sosial. Oleh karena itu, diperlukan sebuah gerakan untuk mencegah fenomena ini supaya tidak terjadi. Berbagai kampanye sosial dipublikasikan untuk meningkatkan kesadaran, mengedukasi, dan menyampaikan mitigasi kepada masyarakat, serta meminimalisir korban Cyberbullying di berbagai belahan dunia. Kampanye sosial tersebut dirancang oleh berbagai segmen masyarakat, dari perusahaan multimasional, Lembaga Sosial Masyarakat (LSM), Organisasi pemerhati anak dunia, dan bahkan individual professional serta mahasiswa perguruan tinggi di berbagai negara.

Mara Panzar adalah seorang desainer grafis dari New York, Amerika Serikat membuat sebuah kampanye mengenai cyberbullying atau perundungan maya "No Bull" pada tahun 2011 yang menggunakan berbagai macam media di antaranya poster, augmented reality, pameran karya desain, merchandise, dan permainan interaktif (Panzar, 2011). Kampanye ini dirancang 
untuk organisasi nirlaba bernama No Bull yang mengajari anak usia 12-17 tahun untuk dapat mengatasi perundungan. Seluruh media tersebut saling berkesinambungan dan beralur. Kampanye ini dirancang saat Panzar menempuh pendidikan sarjana dan membawa Mara Panzar mendapat penghargan Pratt Circle Award tahun 2013 (Panzar, 2015).

Identitas visual kampanye ini terdiri atas 2 elemen, pertama adalah ilustrasi berupa siluet yang mirip dengan kepala banteng dengan tanda $X$ pada bagian tengah dan kedua adalah nama kampanye "No Bull" (Panzar, 2012). Kampanye diawali dengan perkenalan 3 faksi yang masing-masing mewakili karakter tertentu dalam fenomena cyberbullying melalui poster. Masing-masing faksi memiliki warna dan tagline tersendiri. Warna kuning dengan tagline "Your Pain Amuses Me", warna biru dengan tagline "Your Misery Fuels Me", dan warna merah dengan tagline "Your Torment Justifies Me." Kemudian target audience bisa mendapatkan papercraft dari karakter-karakter yang mewakili masing-masing faksi, lengkap dengan deskripsi dan latar belakang ceritanya. Papercraft ini dapat dirangkai sendiri oleh target audience, kemudian target audience diarahkan untuk saling berinteraksi dengan augmented reality yang dihasilkan melalui gawai mereka.
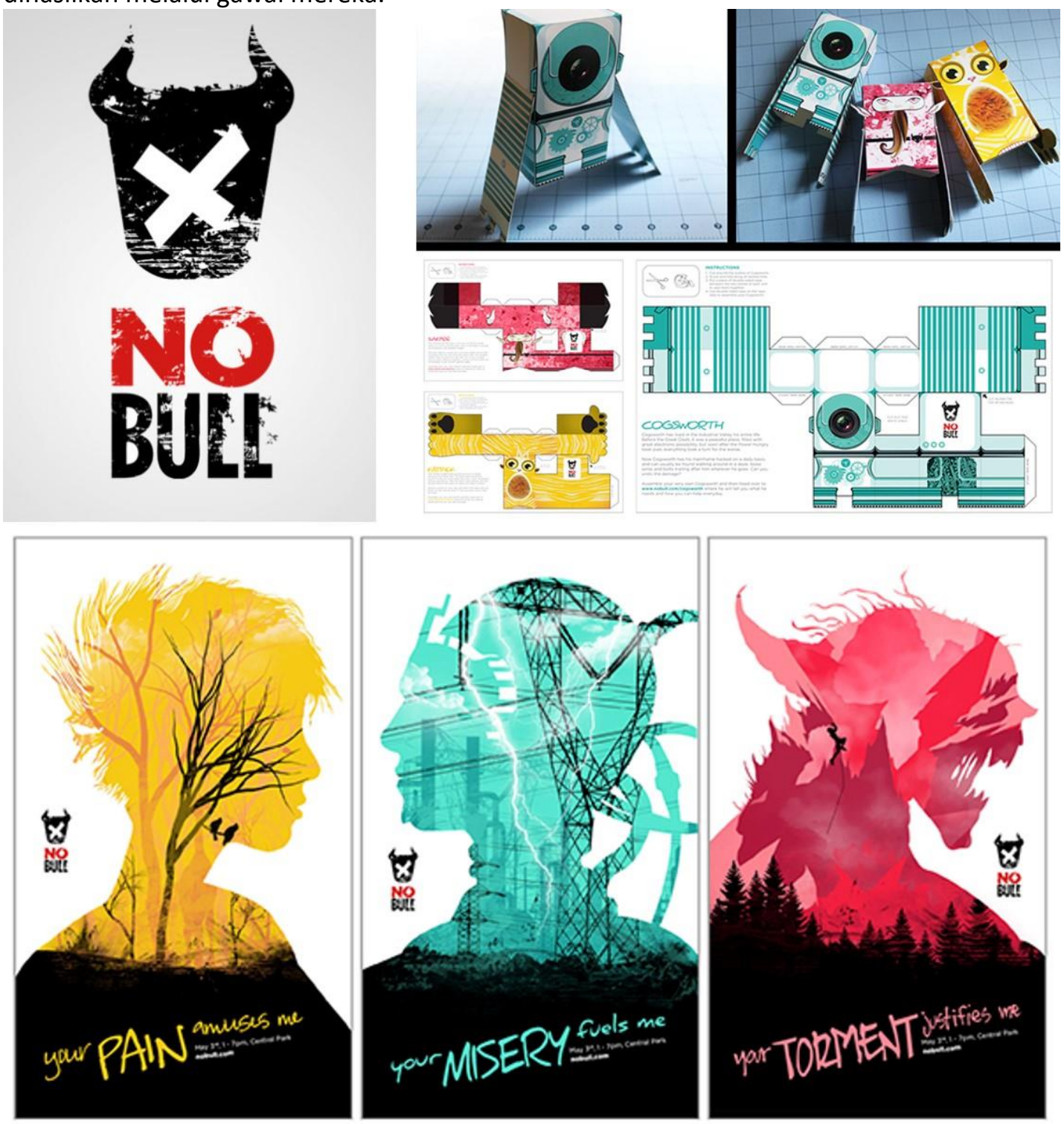

Gambar 1. Logo Kampanye "No Bull" (kiri atas), Papercraft untuk augmented reality (kanan atas), dan Poster yang menggambarkan 3 faksi (bawah) dalam kampanye anti Cyberbullying "No Bull." Sumber: Panzar (2011); Panzar (2012) 
Media berikutnya adalah kartu undangan interaktif dengan bentuk kertas dilipat yang terlihat biasa ketika belum dibuka dengan logo "No Bull" di depannya dan copy "Sometimes it happens without any intent." Target audience harus membuka undangan secara paksa karena halaman dalamnya direkatkan untuk memunculkan efek seakan-akan merobek jantung dari ilustrasi berupa robot yang ada di dalamnya dengan copy "You Broke My Heart, please fix it. nobull.com" dan sebuah peta yang mengarahkan target audience ke lokasi tertentu. Peta dalam undangan tersebut mengarahkan target audience ke sebuah area pameran karya yang di desain menyerupai dunia khayalan tempat para karakter dari 3 faksi tadi hidup, di sepanjang jalur sirkulasi menuju area pameran karya, tersebar sejumlah stiker mural pada tembok dan lantai yang menunjukkan lingkungan dari ketiga faksi dengan tanda panah yang menunjukkan destinasi yang harus dicapai oleh target audience.
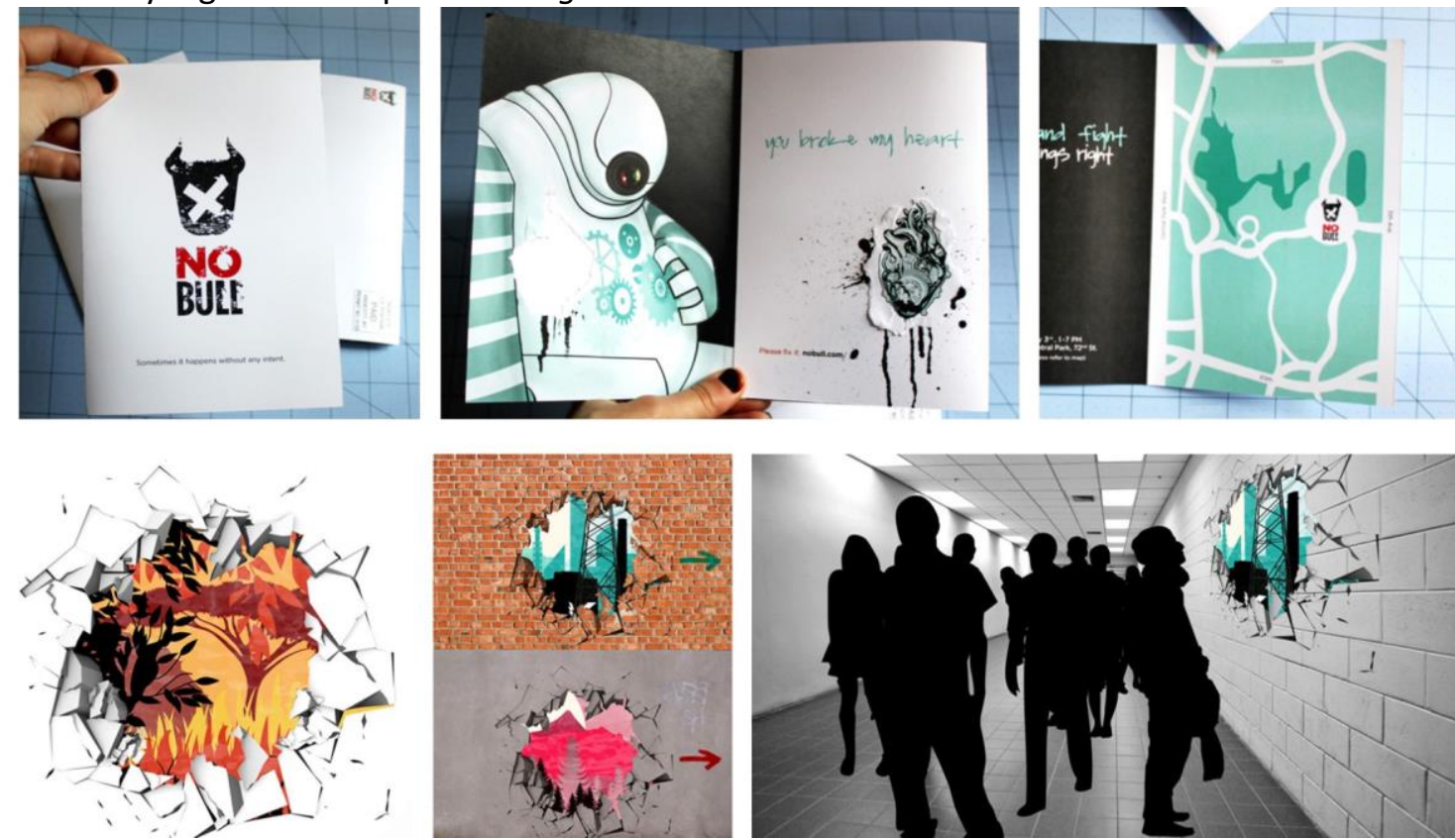

Gambar 2. Undangan interaktif dengan ilustrasi robot dan peta (atas) dan stiker mural di sepanjang jalur sirkulasi menju area pameran karya (bawah). Sumber: Panzar (2011)

Di dalam area pameran karya terdapat Ipad Station, serta desain-desain lainnya yang ditempatkan agar supaya target audience bisa berinteraksi satu sama lain dalam bentuk permainan interaktif yang memerlukan kerjasama. Selanjutnya target audience atau khalayak sasaran dapat memilih dan membeli merchandise berupa kaos dengan tiga pilihan desain yang mewakili faksi-faksi yang dirasa cocok dengan karakter masing-masing. Di dalam area pamer tersebut, selain permainan interaktif, media yang memanfaatkan augmented reality, juga dirilis laman daring (website) dengan interface yang berisi permainan-permainan interaktif yang memberikan berbagai informasi mengenai cyberbullying, baik pelaku maupun korban, sesuai dengan karakteristik masing-masing faksi. 

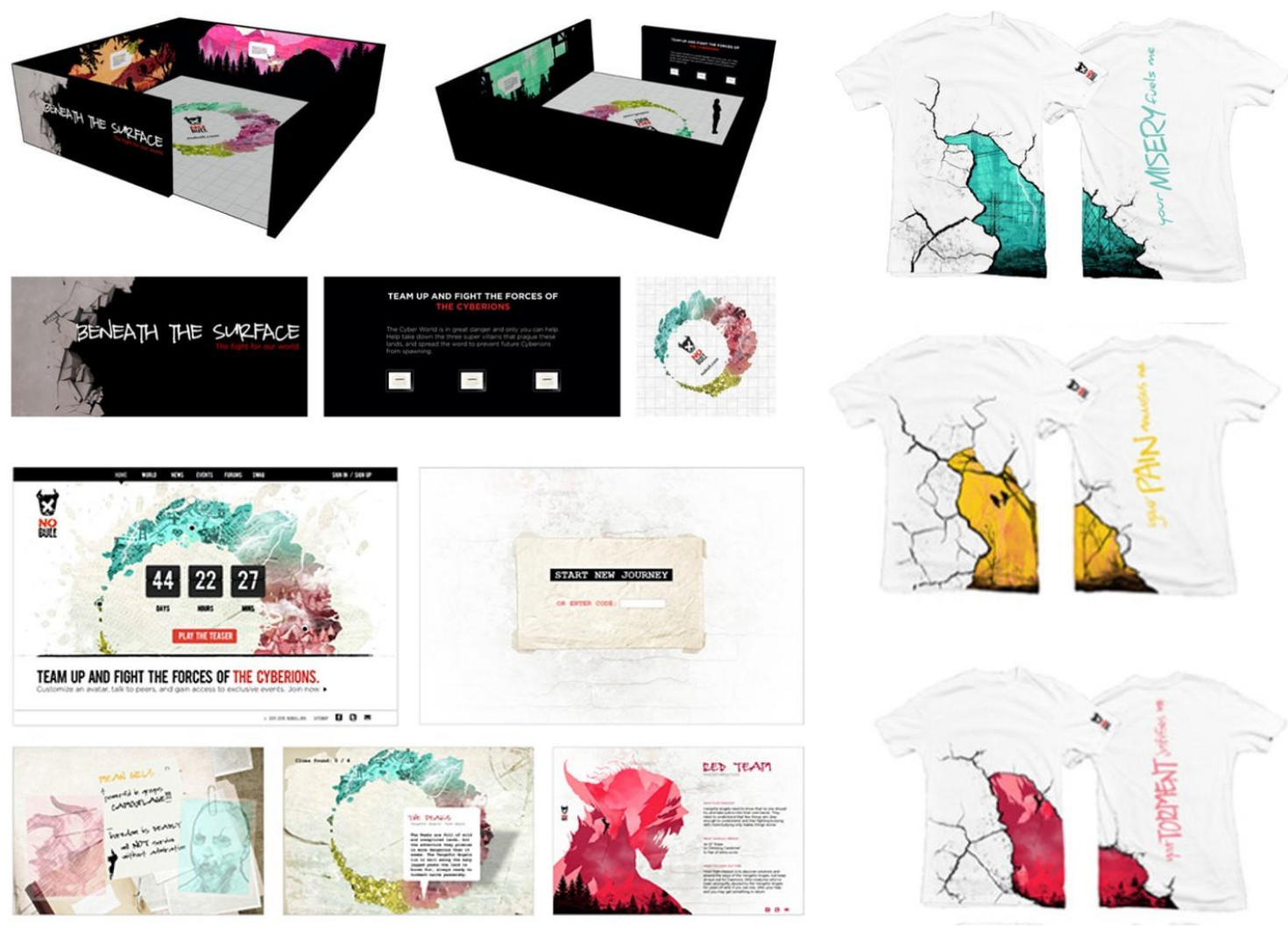

Gambar 3. Desain Area Pameran Karya interaktif (kiri atas), laman daring berisi informasi mengenai Cyberbullying dan permainan interaktif (kiri bawah), dan T-Shirt sebagai merchandise dengan desain 3 faksi (kanan) dalam kampanye anti Cyberbullying "No Bull." Sumber: Panzar (2011)

Kampanye "No Bull" karya Mara Panzar ini merupakan bagian dari implementasi ilmu Desain Komunikasi Visual, khususnya dalam mengomunikasikan pesan persuasif melalui media visual dalam kerangka kampanye sosial. Dalam merancang pesan persuasif tersebut, terdapat model komunikasi yang dipublikasikan oleh Dentsu, sebuah biro periklanan global yang disebut dengan model komunikasi AISAS. Penelitian ini adalah kajian yang membedah bagaimana kampanye sosial "No Bull" karya Mara Panzar ini dipetakan berdasarkan model komunikasi AISAS agar dapat menjadi panduan dalam mengembangkan pesan persuasive melalui serangkaian media komunikasi visual yang terintegrasi.

\section{Metode}

Telaah akan kampanye sosial No Bull karya Mara Panzar dilakukan dengan analisis empiris deskriptif dengan penjabaran pesan persuasif berbasiskan model komunikasi AISAS.

\section{Kampanye Sosial}

Menurut Rogers dan Storey dalam Budiwaspada dan Mansoor (2020), kampanye adalah serangkaian tindakan komunikasi secara persuasif, berkelanjutan, dan pada kurun waktu tertentu yang dirancang dan direncanakan dengan tujuan menciptakan efek tertentu di masyarakat. Adapun kampanye sosial adalah bentuk komunikasi persuasi yang dilakukan untuk mengubah kebiasaan, pola pikir, nilai, dan atau prasangka di masyarakat dan pada akhirnya khalayak sasaran diharapkan melakukan sesuatu yang dianjurkan dalam pesan kampanye (Yusadhi dan Mansoor, 2020; Budiwaspada dan Mansoor, 2020). 


\section{Model Komunikasi AISAS}

Model AISAS adalah model komunikasi yang dikembangkan oleh biro periklanan multinasional Dentsu (Sugiyama dan Andree, 2011). AISAS sendiri adalah akronim dari Attention, Interest, Search, Action, dan Share yang merupakan pengembangan dari AIDMA, akronim dari Attention, Interest, Desire, Memory, dan Action (Chen dan Huang, 2011). Attention adalah upaya untuk membuat sebuah iklan agar menyita perhatian khalayak sasaran. Adapun Interest adalah proses komunikasi berikutnya, yang membuat calon konsumen tertarik dengan produk atau pesan yang dibangun. Ketertarikan itu bisa muncul karena terdapat aspek atau hal yang sejalan dengan minat khalayak sasaran. Sebagai tambahan, di era komunikasi yang intens melalui media interaktif khususnya internet dan media sosial, ketertarikan ini bisa juga terjadi apabila khalayak sasaran merasa ada yang relevan antara minat mereka dengan informasi yang dipaparkan di laman daring yang dituju, sehingga bagaimana menyusun konten dalam sebuah laman daring yang sesuai dengan tujuannya serta membangun pengalaman yang tepat, nyaman, dan menyenangkan saat orang menggali informasi di laman tersebut dapat meningkatkan ketertarikan khalayak sasaran.

Search merupakan sebuah keleluasaan baru bagi masyarakat dengan adanya laman pencari informasi Google, Mozilla, dan sejenisnya sebelum mengambil keputusan. Product review, tulisan di blogs, laman daring resmi ataupun agregat mengenai produk, jasa, atau lainnya, mailing list, forum, dan aplikasi media sosial dapat terpampang dengan jelas dalam mesin pencari informasi dengan memasukkan kata kunci pencarian yang tepat. Kemudian Action adalah tindakan khalayak sasaran, di sinilah interaksi antara khalayak sasaran dengan produk, jasa, atau pesan sosial tercipta. Serta pada akhirnya Share adalah dampak dari pengalaman yang didapat oleh khalayak sasaran atas interaksi mereka dengan produk/brand, jasa, atau aktivitas lainnya dibagikan kepada pihak lain melalui testimoni, email, chat, blogs, milis, online forum, dan media sosial. Pengalaman ini dapat berupa pengalaman positif maupun negatif yang akan mudah tersebar ke banyak orang, dan juga akan terendus oleh search engine menjadi sebuah siklus yang berkelanjutan. Aktivitas Search, Action dan Share merupakan domain khalayak sasaran yang dapat dikatakan tidak terikat erat dengan aktivitas Awareness dan Interest yang merupakan domain komunikasi pihak pembuat pesan. 

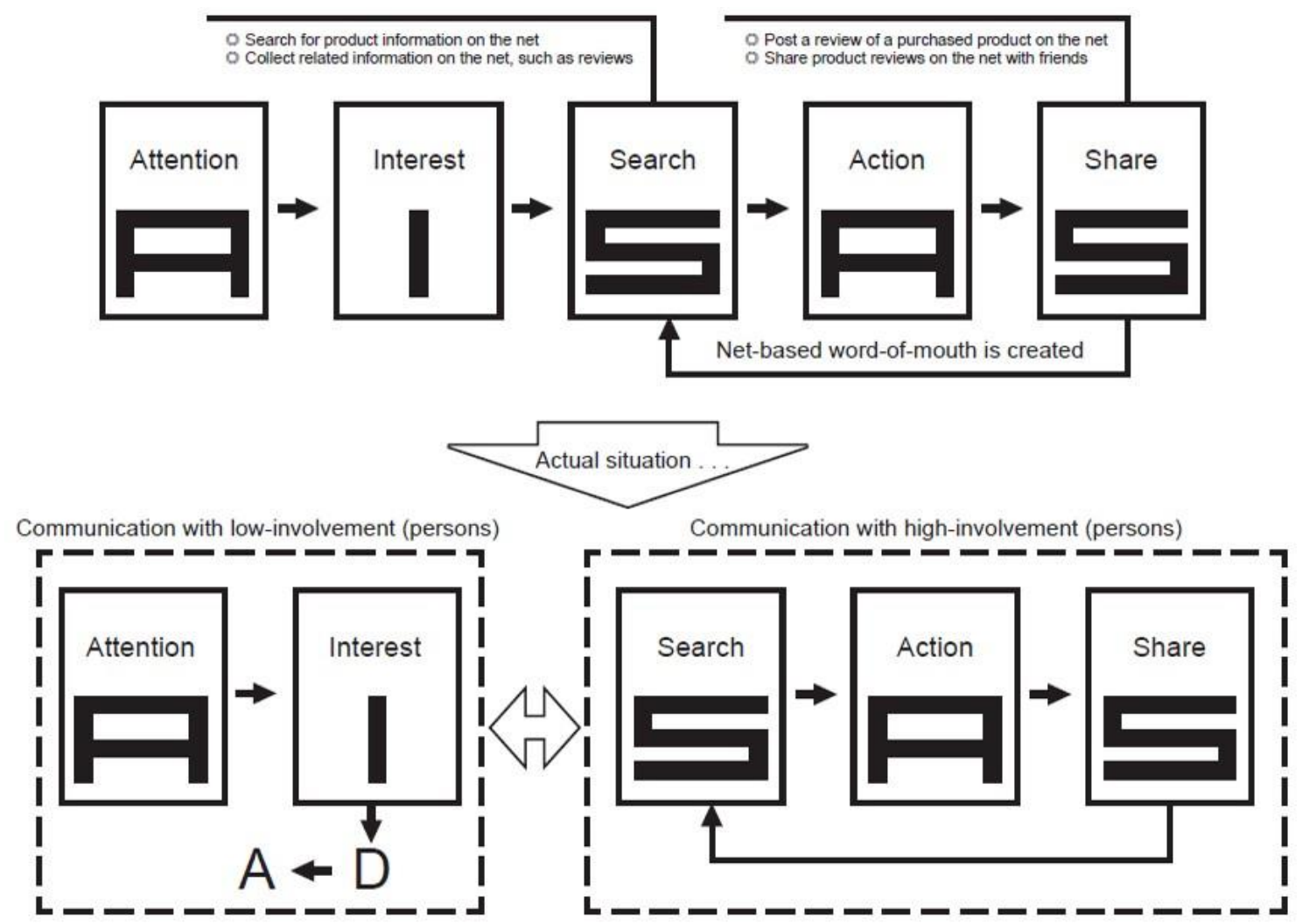

Gambar 4. Model AISAS dan Interaksi yang terjadi. Sumber: Mochizuki (2014)

\section{Hasil dan Pembahasan}

Mara Panzar menggunakan media poster, undangan interaktif, papercraft, stiker mural, stiker yang dibagikan, dan T-shirt dalam kampanye "No Bull." Telaah atas implementasi model komunikasi AISAS dalam kampanye "No Bull," dilakukan berdasarkan pembobotan pesan AISAS dalam sistem integrasi media kampanye dan distribusi informasi dalam media kampanye berdasarkan struktur model komunikasi AISAS.

\section{Attention}

Mara Panzar merancang 3 Poster dengan desain warna dan copy yang menunjukkan karakter dari 3 faksi berbeda tetapi masih disajikan dengan struktur dan gaya visual yang seragam. Poster-poster ini ditempatkan di mana khalayak sasaran yaitu siswa tinggi aktivitas interaksinya, seperti plaza, halte, selasar, dan ruang terbuka di depan bangunan kampus (courtyard) dalam kompleks Pratt Institute. Melalui poster ini, perhatian khalayak terpaut dengan visualisasi yang unik dan berulang. Poster ini tidak memberikan begitu banyak informasi, tetapi dengan warna yang dominan yaitu merah, kuning, dan biru spotlight disertai copy yang singkat dengan permainan skala menjadikannya sangat mudah untuk menarik perhatian khalayak sasaran. Visualisasi imajinatif yang menggunakan warna dominan tersebut memenuhi $60-70 \%$ bidang poster dengan copy yang menggunakan teknik ilustrasi diapositif berupa warna spotlight di atas bidang hitam menjadikan poster tersebut sangat dominan dibandingkan media komunikasi lain maupun elemen arsitektur di sekitarnya. Adapun aspek attention pada desain undangan interaktif yang disebar secara acak kepada khalayak sasaran dicetuskan melalui visual logo yang memenuhi $60 \%$ bidang kertas. 

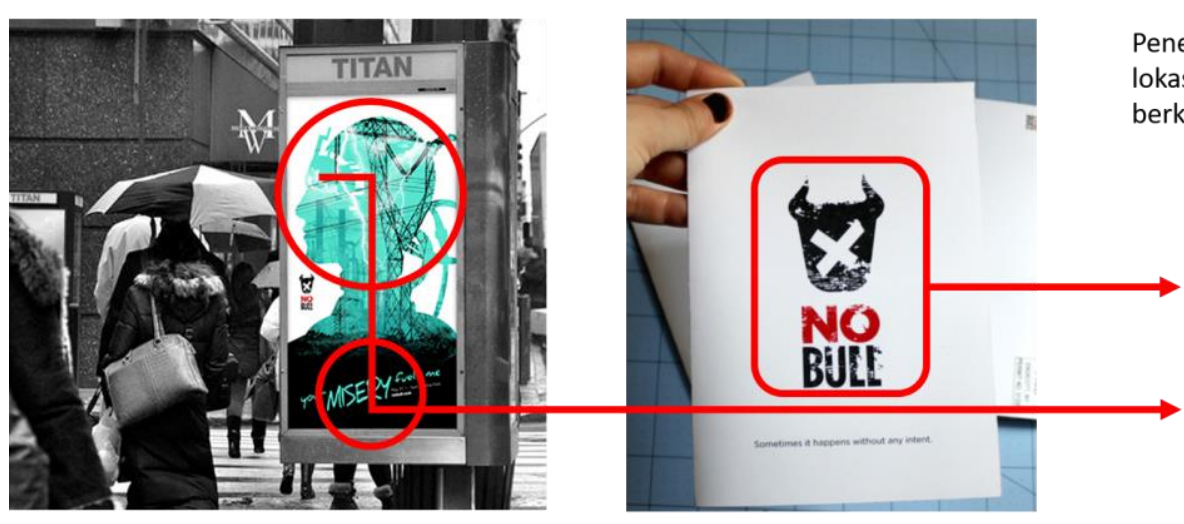

Penempatan Poster pada lokasi di mana siswa banyak berkumpul atau lalu lalang
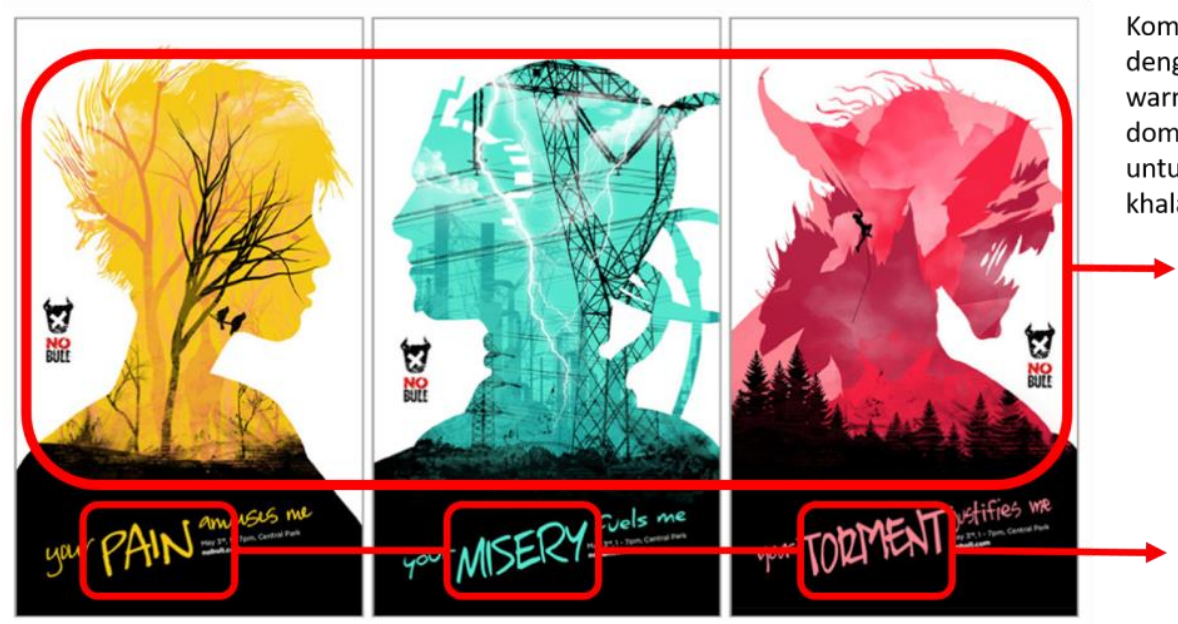

Komposisi Desain Poster dengan perbedaan pada warna, visualisasi yang dominan, dan (skala) copy untuk menarik perhatian khalayak sasaran

Gambar 5. Poster dan undangan yang menitikberatkan pada aspek pilihan warna, bentuk siluet yang dimunculkan, permainan skala pada copy dan logo yang dominan.

\section{Interest dan Search}

Bagian isi undangan interaktif yang tidak mudah dibuka kecuali bila dipaksa sampai robek memunculkan aspek komunikasi Interest. Diperkuat dengan visualisasi robot dengan jantung yang tercerabut yang berbeda dengan siluet yang muncul pada poster, diikuti dengan adanya peta dengan lokasi serta waktu memberikan kesan misterius untuk mencetuskan emosi yang diperkuat dengan copy yang menegaskannya berupa "you broke my heart" dan rasa ingin tahu khalayak sasaran untuk melakukan aksi menelusuri atau mencari (search) dengan copy yang berbentuk perintah, yaitu "Team up and fight to make things right." Aksi ini diperkuat dengan stiker mural yang menduplikasi warna dari visualisasi poster dengan tanda panah. Adapun visualisasi dari stiker tersebut mengilustrasikan dinding yang terbobol pada sisi lain yang menunjukkan lingkungan dari salah satu faksi korban perundungan. Stiker mural tersebut ditempatkan pada jalur sirkulasi siswa Pratt Institute yang memberikan panduan arah seakan mengajak khalayak sasaran untuk bergerak menuju destinasi yang ditunjukkan oleh peta dalam undangan. 


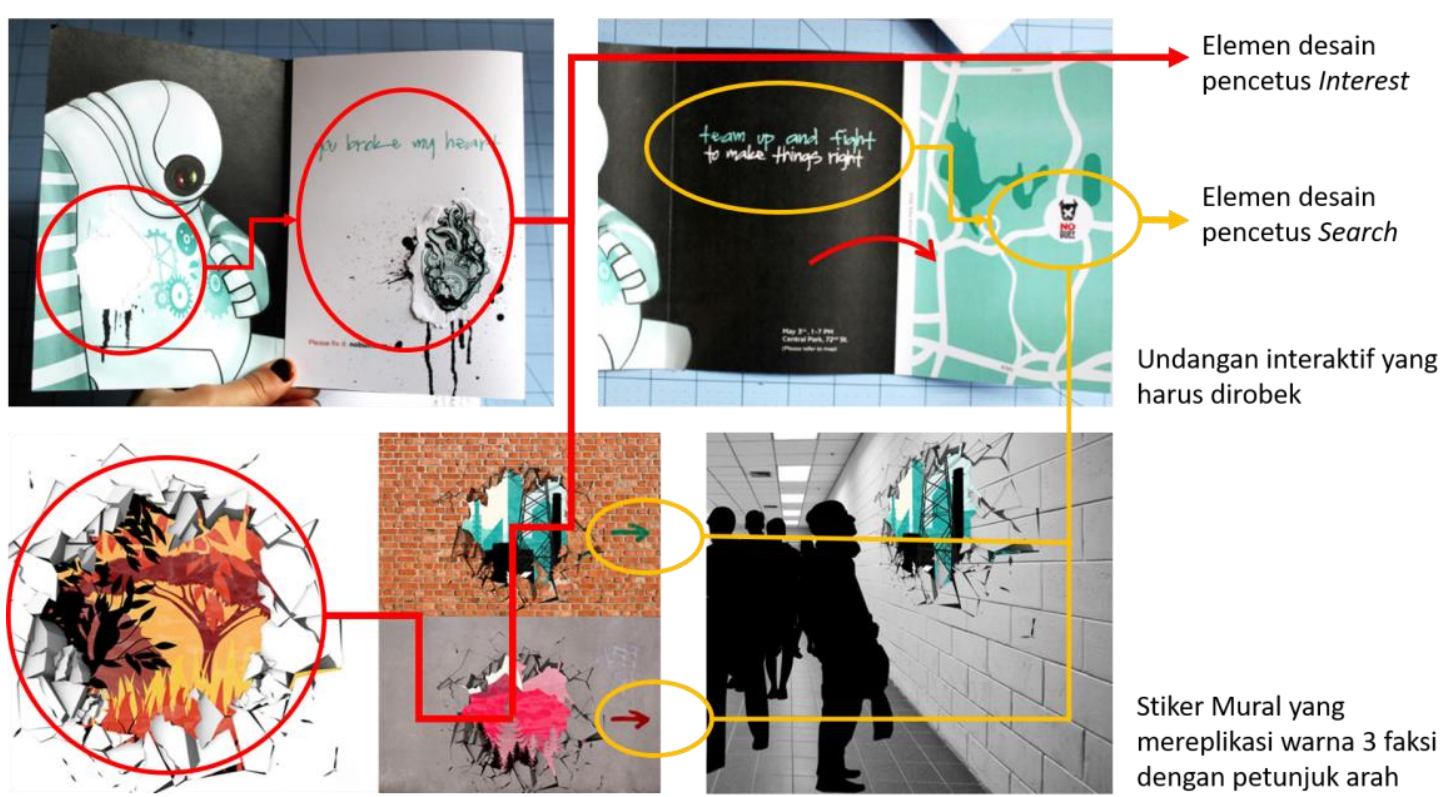

Gambar 6. Undangan dan Stiker Mural yang mencetuskan aspek komunikasi Interest dan Search

\section{Action}

Aspek komunikasi action adalah saat dimana khalayak sasaran tergerak untuk pergi menuju destinasi yang ditunjukkan dalam undangan interaktif dan tanda panah penunjuk arah pada stiker mural. Sebelum itu, aspek aksi juga sudah dilakukan oleh mereka yang menggunakan paksaan dalam membuka undangan sehingga terobek untuk dapat dibaca isinya. Aksi ini merepresentasikan aktivitas perundungan yang dilakukan oleh para perundung, yaitu pemaksaan kehendak atau kepentingan terhadap korban. Khalayak sasaran dipaksa bermain peran oleh Mara Panzar dari perannya sebagai perundung (yang merobek undangan) berubah menjadi pihak yang menyokong korban perundungan melalui ajakan untuk berkelompok dan memperbaiki kerusakan yang terjadi dengan bergerak ke tempat yang dituju, yaitu wilayah yang berisi karya media interaktif dengan memanfaatkan augmented reality.

Dalam wilayah tersebut, khalayak sasaran diajak untuk mengeksplorasi berbagai permainan interaktif yang harus diselesaikan secara kolaboratif dari pengunjung lain yang mengambil peran yang berbeda. Pada akhirnya, tujuan dari kampanye ini adalah agar khalayak sasaran dapat membangun kinerja tim berbasis prinsip saling mempercayai. Adapun konsep dari karya-karya yang ditempatkan di area pameran adalah bahwa adanya dunia virtual yang selalu hadir di balik dunia tempat manusia berada. Di dunia tersebut, hidup para korban perundungan berada melalui representasi dari 3 faksi dalam kampanye sosial tersebut. Ketiga faksi tersebut juga merepresentasikan jenis perundungan maya (cyberbullying) serta dampak psikis yang ditimbulkan kepada korban perundungan, yaitu sakit secara fisik (pain), penderitaan (misery), dan tersiksa atau menyiksa (torment). Visualisasi dari ketiga faksi tersebut dirancang untuk menggambarkan lingkungan psikis, kisah latar belakang, dan kondisi korban perundungan serta modus operandi dari setiap jenis perundungan maya.

Khalayak sasaran dapat berinteraksi dengan lainnya melalui Ipad Station atau gawai lainnya untuk menyelesaikan misi dan memahami bahwa setiap faksi merupakan representasi dari kelompok korban perundungan yang memiliki cara yang berbeda untuk menghadapi perundungan. Setiap faksi membutuhkan solusi pemulihan yang berbeda akan tetapi tetap membutuhkan satu dasar pijakan yang sama, yaitu saling mempercayai untuk bersama mengatasi perundungan. Area pameran karya dan permainan interaktif tersebut dilengkapi dengan laman daring yang berisi informasi yang terkait dengan perundungan maupun kampanye sosial "No Bull." 


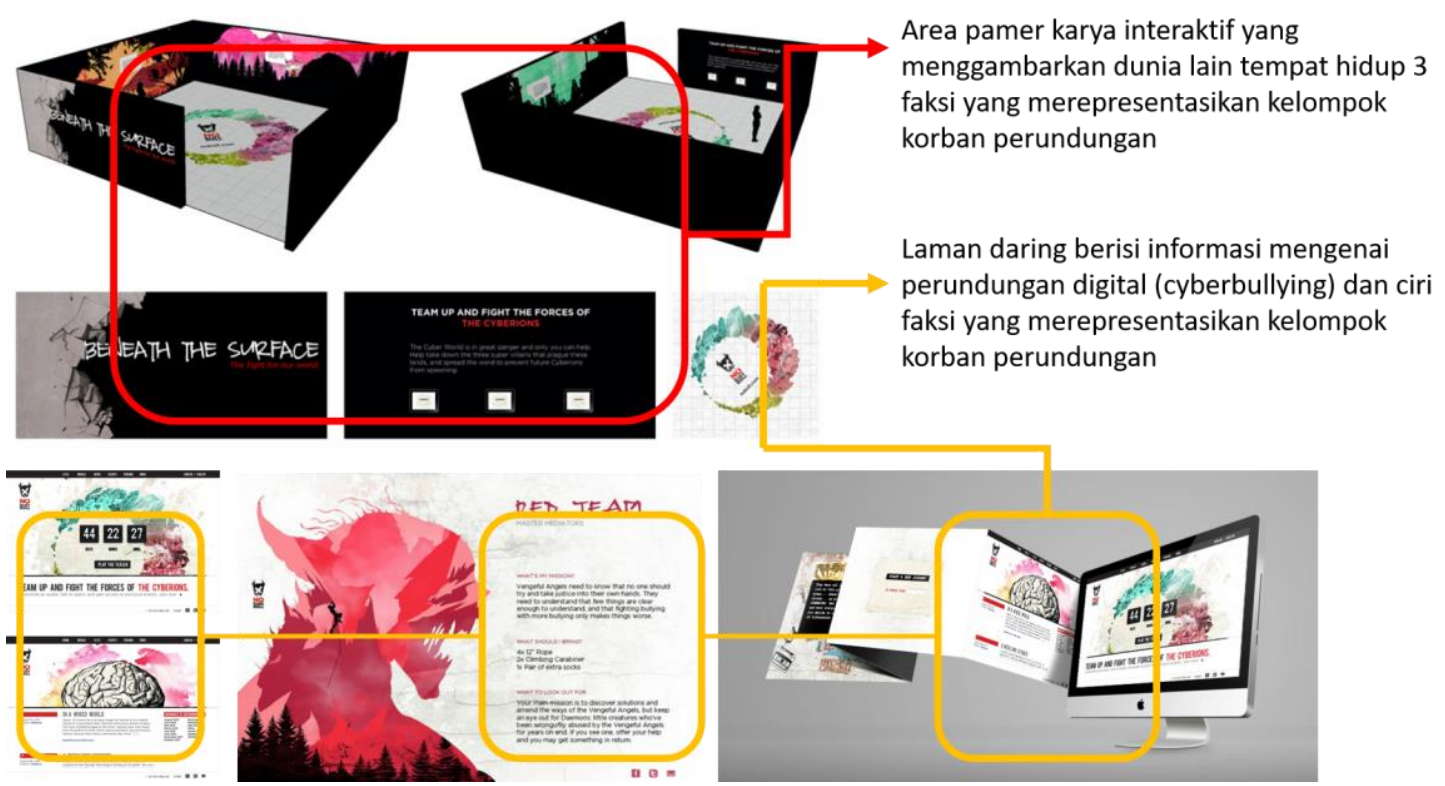

Gambar 7. Area pameran karya interaktif dan laman daring berisi informasi kampanye "No Bull."

Share atau Berbagi Pengalaman atas Aksi (Action) yang dilalui

Share adalah dimana khalayak sasaran dapat berbagi pengalaman, empati, atau dukungan terhadap suatu produk, jasa atau pesan tertentu. Dalam kampanye "No Bull," aktivitas share dominan diangkat oleh Mara Panzar melalui tiga merchandise kampanye yaitu T-shirt, papercraft, dan stiker yang dibagikan. Pengunjung area pameran karya dan permainan interaktif dapat menunjukkan preferensi faksi mereka melalui papercraft yang dapat dirangkai menjadi robot yang dapat berinteraksi melalui fitur augmented reality dan atau $T$-shirt yang mereka gunakan yang memiliki karakteristik desain berbeda antara satu faksi dengan faksi lainnya.

Khalayak sasaran utama kampanye ini adalah siswa khususnya siswa Pratt Institute, memiliki kecenderungan untuk pamer kepada teman-teman sebayanya. Pada desain pameran yang sifatnya monumental, mereka dapat mendokumentasikan foto maupun video diri mereka di sekitar area pameran, ataupun membagikan capaian mereka entah itu skor dalam permainan, maupun tingkatan level yang telah dicapai dalam permainan yang disediakan dalam laman daring melalui media sosial. Dari ketiga merchandise kampanye tersebut, 2 merchandise, yaitu stiker dan T-Shirt menggunakan elemen yang dominan dalam kampanye, yaitu visualisasi latar salah satu faksi dengan warna yang dominan. Adapun merchandise papercraft yang merepresentasikan korban perundungan, secara visualisasi kurang menunjukkan kesinambungan visual dalam kampanye.

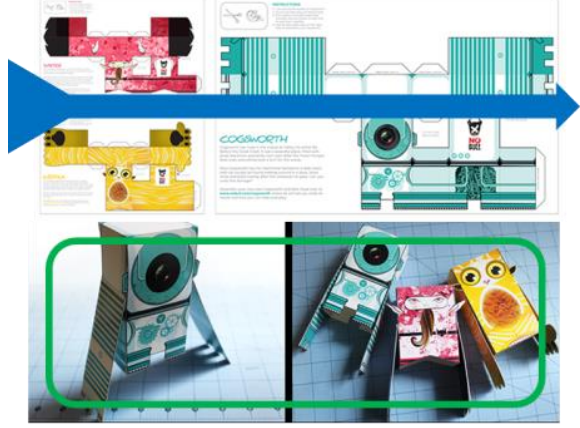

\section{ACTION}

Merangkai papercraft dan memakai T-Shirt

Gambar 8. Merchandise kampanye berupa papercraft dan T-shirt sebagai perwujudan aspek komunikasi Share

SHARE

Berinteraksi dengan khalayak sasaran lain menggunakan AR (Papercraft) \& berbagi pengalaman kolaboratif ( $T$-Shirt)

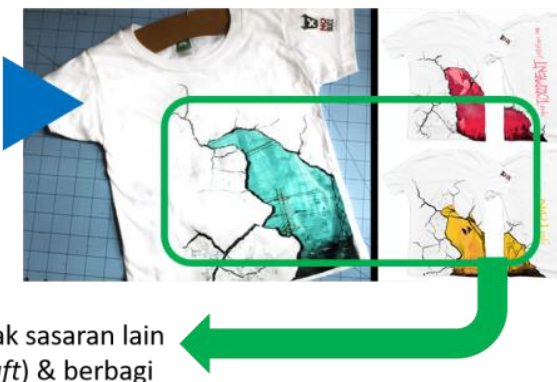




\section{AISAS dan Integrasi Media dalam Kampanye "No Bull"}

Model komunikasi AISAS terbagi atas dua tahap, yaitu aktivitas awareness dan interest dengan intensitas keterlibatan khalayak sasaran yang rendah dan aktivitas search, action, dan share dengan intensitas keterlibatan khalayak sasaran yang tinggi. Dari sisi lain, dapat dikatakan bahwa pemilik pesan kampanye harus memaksimalkan pemanfaatan aspek desain komunikasi visual untuk menghasilkan pesan yang menarik perhatian dan minat khalayak sasaran dengan kuat sebagai amunisi untuk keterlibatan mereka pada aspek aktivitas komunikasi meninggi. Dampak dari pemeranan tersebut adalah terdistribusinya fungsi dari elemen desain komunikasi visual (DKV) berupa ilustrasi, warna, komposisi, dan copy untuk tidak selalu menjadi sebuah pesan komunikasi yang utuh atau lengkap. Sebagai contoh, tidak setiap media harus memiliki elemen DKV yang merepresentasikan keberadaan semua aspek komunikasi dalam model komunikasi AISAS. Oleh karena itu dibutuhkan integrasi antar media kampanye untuk menghasilkan pesan berbasis model komunikasi AISAS yang utuh.

Dalam kasus media kampanye yang dirancang oleh Mara Panzar dalam kampanye sosial cyberbullying "No Bull," tidak setiap media memiliki elemen DKV yang mengomunikasikan pesan AISAS secara utuh. Poster, undangan interaktif, laman daring, dan area pameran karya interaktif adalah media dengan pemanfaatan elemen DKV terbanyak untuk mengomunikasikan AISAS. Sebagai contoh pada poster, visualisasi berupa siluet wajah yang unik, warna yang kontras dengan ilustrasi lingkungan yang asing, dan logo kampanye merupakan bagian dari komunikasi AISAS yang berperan untuk menarik perhatian khalayak sasaran (awareness). Adapun pilihan bentuk huruf dan perbedaan skala copy yang menunjukkan emosi negatif berperan memunculkan rasa ingin tahu (interest). Struktur informasi pada mayoritas media yang digunakan untuk menarik perhatian dan memunculkan rasa ingin tahu khalayak sasaran konsisten dengan penggunaan center margin untuk mengomposisikan elemen desain komunikasi visualnya, khususnya pada poster dan sampul undangan.

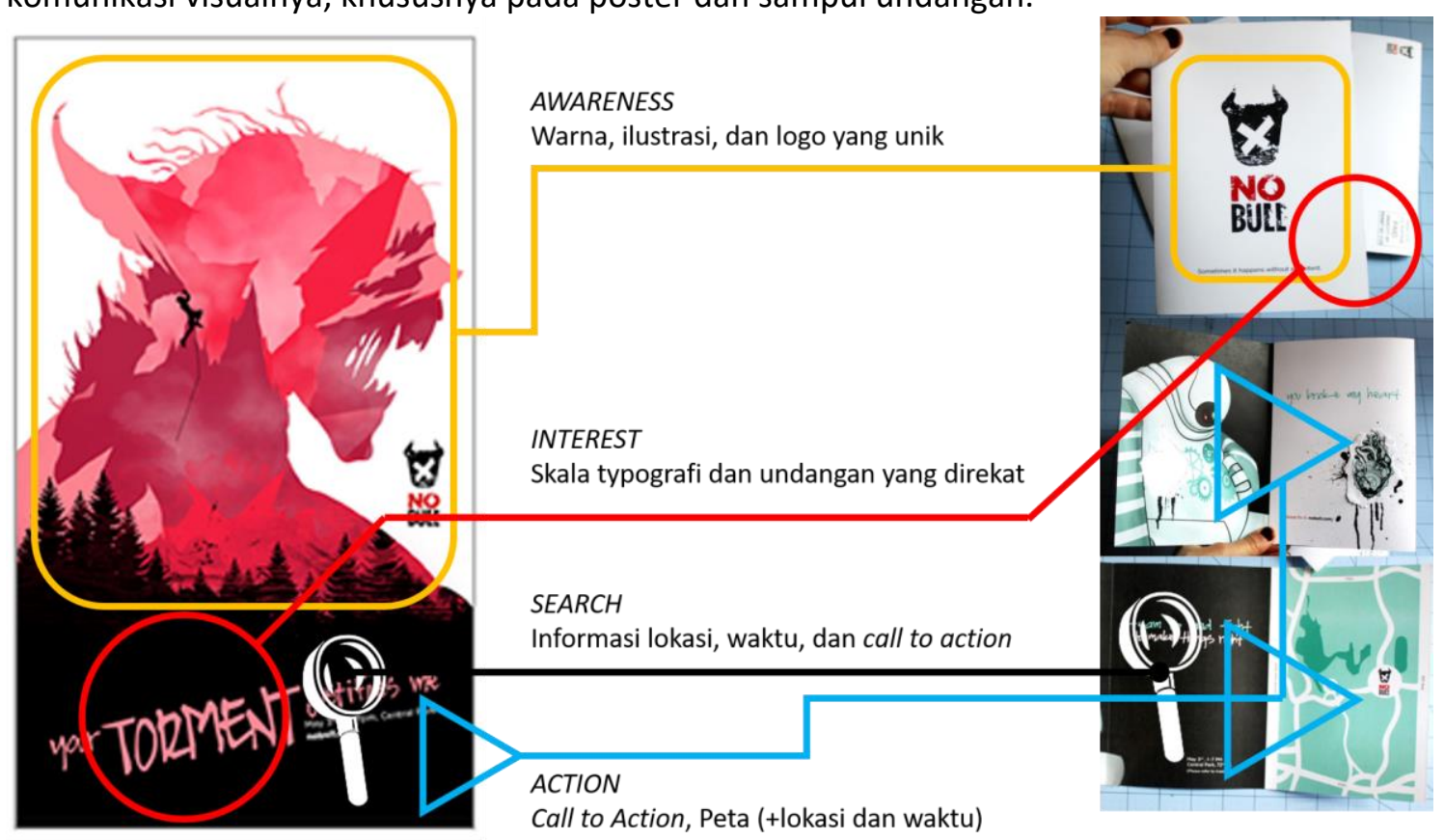

Call to Action, Peta (+lokasi dan waktu) 


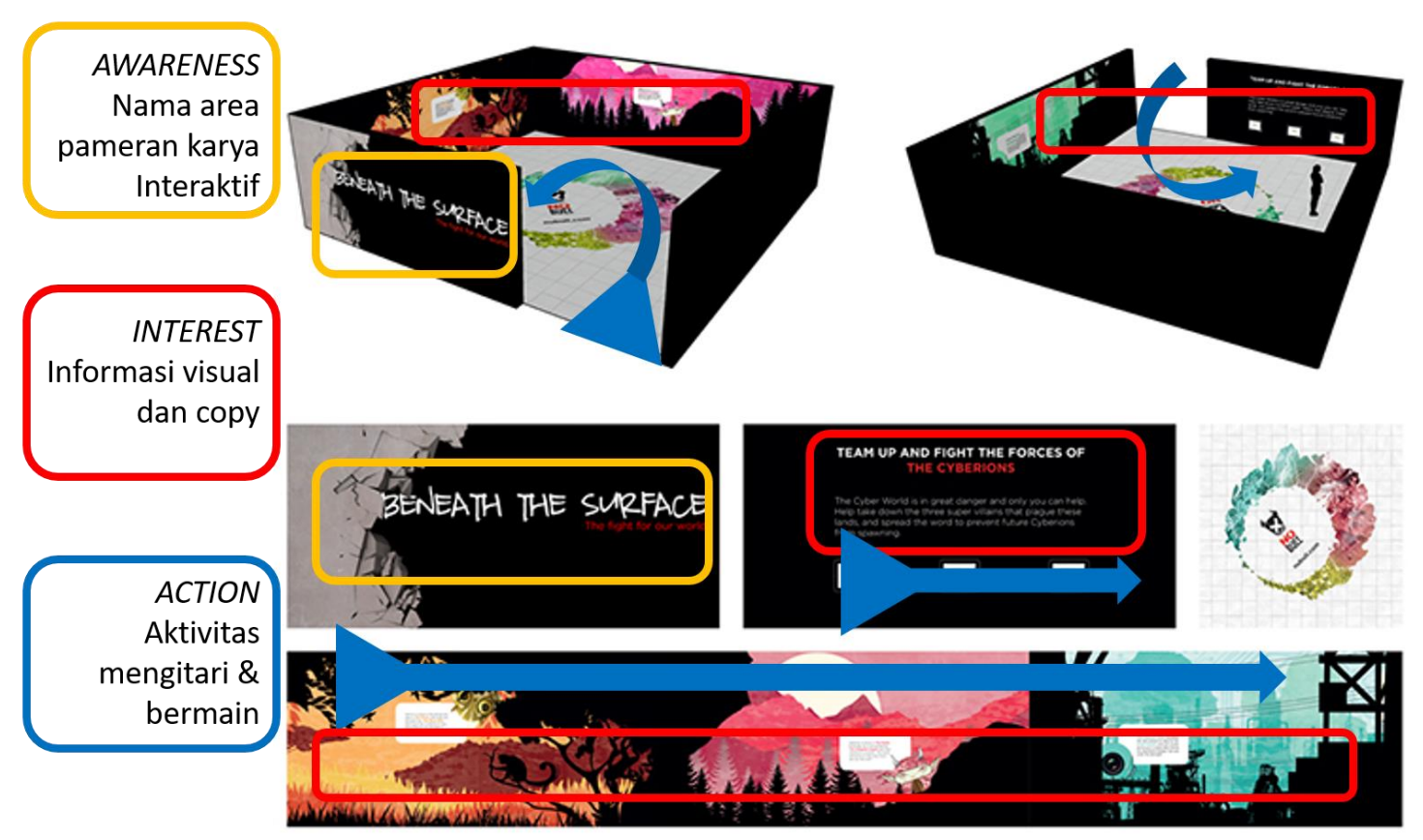

Gambar 9. Pemetaan fungsi elemen dkv dalam menyampaikan aspek komunikasi AISAS pada media poster (kiri atas) dan undangan interaktif (kanan atas), serta area pameran karya interaktif (bawah).

Pada sejumlah media lainnya, khususnya stiker mural, papercraft, dan T-shirt, aspek komunikasi AISAS tidak diimplementasikan sepenuhnya, tetapi lebih pada menekankan pada aspek berbagi pengalaman kepada jejaring khalayak sasaran melalui bukti partisipasi aktif mereka dalam kampanye tersebut. Dapat disimpulkan bahwa tidak semua media dalam kampanye harus mengimplementasikan model komunikasi AISAS yang disajikan melalui elemen dkv akan tetapi dapat diterapkan pembobotan yang relevan sesuai dengan fungsi dari media tersebut dirancang dan ditempatkan pada lingkungan. Akan tetapi keseluruhan media tersebut secara terintegrasi menyampaikan pesan kampanye sosial "No Bull" secara utuh dan menimbulkan partisipasi aktif dari khalayak sasaran untuk menghasilkan siklus komunikasi yang utuh dari model komunikasi AISAS. Kemudian hal yang menarik untuk digarisbawahi adalah, Mara Panzar menggunakan warna menjadi elemen desain komunikasi visual penghubung antar media yang dominan selain logo kampanye, akan tetapi visualisasi robot yang direpresentasikan sebagai korban perundungan terasa kurang erat kaitannya dengan kampanye karena elemen warna yang dominan tersebut mendapat proporsi ruang yang kurang signifikan.

\section{Simpulan}

Kampanye sosial adalah bentuk komunikasi persuasi yang dilakukan untuk mengubah kebiasaan, pola pikir, nilai, dan atau prasangka di masyarakat untuk kemudian menerapkan dan mengimplementasikan nilai, pola pikir, kebiasaan, dan sikap yang dianjurkan dalam pesan kampanye. Penerapan model komunikasi AISAS dalam kampanye sosial mengubah pola komunikasi pesan kampanye dengan meningkatkan peran khalayak sasaran untuk aktif dalam mendapatkan informasi atau pesan kampanye, mengimplementasikan atau berpartisipasi, serta menjadi agen perubahan yang menyebarluaskan pesan kampanye sosial tersebut kepada khalayak yang lebih luas. Pemilik pesan kampanye sosial memiliki tanggung jawab dalam menyiapkan informasi yang dapat diakses secara menyeluruh oleh khalayak sasaran dengan 
menyediakan perangkat pesan pengumpan yang mengaktivasi secara maksimal keinginantahuan dan rasa penasaran mereka.

Kampanye sosial "No Bull" karya Mara Panzar yang dibuat untuk organisasi nirlaba No Bull adalah kampanye yang menyampaikan pesan sosial bahwa perundungan maya memberikan dampak psikis dan sosial yang merusak korban. Korban perundungan maya membutuhkan dukungan solid banyak pihak yang bekerjasama dengan asas saling percaya untuk dapat memulihkan diri. Kampanye tersebut ditujukan kepada khalayak sasaran utama yaitu siswa, khususnya siswa Pratt Institute sebagai khalayak sasaran yang berperilaku khas yang dimanfaatkan oleh Panzar, yaitu keinginan untuk berinteraksi dan berbagi melalui media sosial. Oleh karena itu, poster dan undangan interaktif merupakan media utama yang berperan kuat membangun aspek komunikasi kesadaran (awareness) dan perhatian (interest) di kalangan khalayak sasaran. Peta pada undangan dan stiker mural memperkuat aspek komunikasi yang menggugah mereka untuk mencari (search) informasi lebih lanjut dengan berbagai aktivitas kolaboratif (action) di area pameran karya interaktif untuk mendapatkan pengalaman melalui simulasi permainan yang merepresentasikan aksi pemulihan korban korban perundungan maya. Pengalaman tersebut dapat ditelusuri kembali dengan mengakses laman daring yang berisi permainan interaktif dan informasi mengenai perundungan maya dan kemudian dikristalisasikan melalui merchandise berbentuk papercraft yang disematkan fitur augmented reality dan T-shirt yang menjadi media penghubung dan memento antara khalayak sasaran dengan masyarakat yang lebih luas (share).

Dengan pembobotan aspek komunikasi yang berbeda pada setiap media, perlu adanya elemen penghubung yang mengikat dan menunjukkan relasi antar media agar media tersebut masih dianggap sebagai satu dari bagian besar media kampanye selain logo. Dalam kampanye sosial "No Bull" karya Mara Panzar ini, 3 warna dominan kampanye yaitu warna merah, kuning dan biru dengan kombinasi warna tint (spektrum intensitas warna sampai putih) merupakan pengikat antar media.

\section{Daftar Pustaka}

American Academy of Pediatrics. "Bullying: It's Not OK." HealthyChildren.org, 2013. https://www.healthychildren.org/English/safety-prevention/at-play/pages/Bullying-ltsNot-Ok.aspx

Budiwaspada, Agung Eko, dan Alvanov Z. Mansoor. "Pemodelan Strategi Kampanye Sosial Pasca Pandemi Covid-19 Berbasis 7 Fase Kesedihan Kubler." Jurnal Desain, vol.7, no. 3, 2020, pp. 207-22, doi: http://dx.doi.org/10.30998/id.v7i3.6335

Chen, Ya Li, and Tao Zhe Huang. "Mechanism Research of OWOM Marketing Based on SOR and AISAS." Advanced Materials Research, vol. 403-408, 2011, pp. 3329-333, doi: https://doi.org/10.4028/www.scientific.net/AMR.403-408.3329

Cyberbullying Research Center. "What Is Cyberbullying?" Cyberbullying Research Center, 2015. https://cyberbullying.org/what-is-cyberbullying

Hinduja, Sameer, and Justin W. Patchin. Bullying beyond the Schoolyard: Preventing and Responding to Cyberbullying. 2nd ed. Thousand Oaks, CA: Corwin, 2015. 
Hinduja, Sameer, dan Justin W. Patchin. "Social Influences on Cyberbullying Behaviors Among Middle and High School Students." Journal of Youth and Adolescence, vol. 42, no. 5, 2013, pp. 711-22, doi: https://doi.org/10.1007/s10964-012-9902-4

Kementrian Pemberdayaan Perempuan Dan Perlindungan Anak. "Bullying." Kementrian Pemberdayaan Perempuan Dan Perlindungan Anak, 15 Maret 2017.

https://www.kemenpppa.go.id/lib/uploads/list/8e022-januari-ratas-bullying-kpp-pa.pdf

Mochizuki, Hiroshi. "Rethinking BtoB Communications from the Perspective of Involvement." Rethinking BtoB Communications from the Perspective of Involvement_Dissertation_Japan BtoB Advertising Association. Japan BtoB Advertising Association, Januari 2014. http://www.bbaa.or.jp/english/dissertation/rethinking/trustee.html

Panzar, Mara. "Mara Panzar." Behance. 2015. https://www.behance.net/mpanzar/resume

Panzar, Mara. "Logo for a Comprehensive Anti-cyberbullying..." Maramade. 1 April 2012. https://maramade.tumblr.com/post/20262714181/logo-for-a-comprehensive-anticyberbullying

Panzar, Mara. "NoBull." Mara Panzar. 2011. http://marapanzar.com/portfolio/nobull/

Sugiyama, Kotaro, and Tim Andree. The Dentsu Way: Secrets of Cross Switch Marketing from the World's Most Innovative Advertising Agency. New York: McGraw-Hill, 2011.

Teenhelp.com. "Cyber Bullying Statistics." Bullying Statistics. 7 Juli 2015. http://www.bullyingstatistics.org/content/cyber-bullying-statistics.html

The Jakarta Post. "Half of All Netizens in Indonesia Victims of Cyberbullying: Study." The Jakarta Post. 16 Mei 2019. https://www.thejakartapost.com/life/2019/05/16/half-of-allnetizens-in-indonesia-victims-of-cyberbullying-study.html

Yusadhi, Egie E., dan Alvanov Z. Mansoor. "KAJIAN KAMPANYE SOSIAL WORLD WILDLIFE FUND: THE LAST SELFIE." Jurnal Bahasa Rupa, vol. 3, no. 2, 2020, pp. 130-37, doi: https://doi.org/10.31598/bahasarupa.v3i2.559 